\title{
Perovskite-Related Oxide Fluorides: The Use of Mössbauer Spectroscopy in the Investigation of Magnetic Properties
}

Frank J. Berry, ${ }^{1, *}$ Colin Greaves, ${ }^{1}$ Nicola N. M. Gurusinghe, ${ }^{1}$ Cathryn Hancock, ${ }^{1}$ Peter Slater, ${ }^{1}$ Michael F. Thomas, ${ }^{2}$ Jose F. Marco ${ }^{3}$

\footnotetext{
1 School of Chemistry, The University of Birmingham, Edgbaston, Birmingham B15 2TT, United Kingdom

2 Department of Physics, University of Liverpool, Liverpool L69 3BX, United Kingdom

3 Instituto de Quimica Fisica, Consejo Superior de Investigaciones Cientificas, Seranno 119, 28006 Madrid, Spain

* Corresponding author's e-mail address: f.j.berry.1@bham.ac.uk
}

RECEIVED: JULY 06, $2015 *$ PUBLISHED: September 24, 2015

THIS PAPER IS DEDICATED TO DR. SVETOZAR MUSIĆ ON THE OCCASION OF HIS 70 ${ }^{\text {TH }}$ BIRTHDAY

Abstract: We review here some of our recent work on the synthesis and characterisation of new perovskite-related oxide fluorides. We demonstrate the use of low temperature fluorination methods for the preparation of new phases with high fluorine contents. We also show how fluorine can be accommodated in different sites according to the structural details of the initial oxide and the fluorine content. Importantly, we describe how Mössbauer spectroscopy is a powerful technique for monitoring changes in cation oxidation state as a result of fluorination and for examining the complex magnetic interactions which result from the accommodation of fluorine within the structures and how these can be related to structural properties and changes to the superexchange pathways.

Keywords: oxide fluorides, Mössbauer spectroscopy, magnetism.

\section{INTRODUCTION}

$\mathbf{T}$ $\mathrm{HE}$ discovery of superconductivity in perovskite-related oxide fluorides of composition $\mathrm{Sr}_{2} \mathrm{CuO}_{2} \mathrm{~F}_{2+x}$ has stimulated considerable interest in the synthesis and characterisation of other inorganic oxide fluorides with related structures. ${ }^{[1-3]}$ We have, in recent years, synthesised new perovskite-related oxide fluorides and have found Mössbauer spectroscopy to be an important technique for investigating magnetic interactions in these materials. In this Feature Article, written to commemorate the $70^{\text {th }}$ birthday of Dr. Svetozar Musić and his contribution to inorganic materials chemistry and Mössbauer spectroscopy in Croatia, we draw together our work to illustrate the power of Mössbauer spectroscopy in the investigation of new inorganic oxide fluorides. We refer the reader to standard texts ${ }^{[4,5]}$ for information concerning the principles of Mössbauer spectroscopy and focus attention in this article on the syntheses of these phases and their magnetic properties.

\section{Synthesis of Inorganic Oxide Fluorides}

The fluorination of inorganic oxides is best achieved by low temperature fluorination routes because the number of oxide fluorides that can be prepared by the standard high temperature solid state routes is limited by the high stability of the simple fluoride starting materials. In terms of low temperature fluorination, a range of fluorinating agents have been used including gaseous fluorine, $\mathrm{NH}_{4} \mathrm{~F}, \mathrm{MF}_{2}$, (M $=\mathrm{Cu}, \mathrm{Ni}, \mathrm{Zn}$ ) and $\mathrm{XeF}_{2}$. More recently a new method has been identified which entails heating the precursor oxide with the polymer poly(vinylidene fluoride). ${ }^{[6]}$ This method was shown to produce high quality samples without significant metal fluoride impurities which are often formed by other low temperature fluorination methods. 


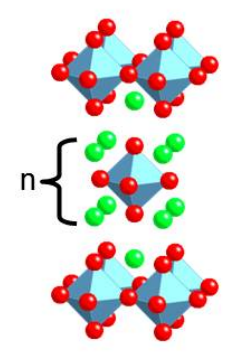

$n=1$

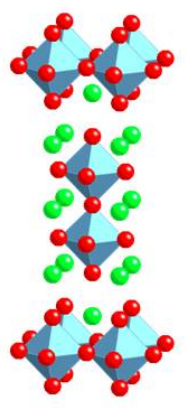

$n=2$

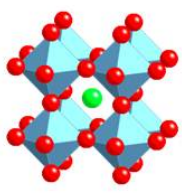

$n=\infty$

Perovskite

$\mathrm{AMO}_{3}$
Figure 1. Representation of the perovskite $\mathrm{AMO}_{3}$ unit cell ( $n=$ infinity) and the Ruddlesden-Popper structures with $n=1$ and $n=2$.

\section{$\mathrm{SrFeO}_{2} \mathrm{~F}$}

Our initial work ${ }^{[7,8]}$ in synthesising and characterising fluorinated cubic perovskite-related oxides used poly(vinylidene fluoride) for the fluorination of the oxygen deficient phase $\mathrm{SrFeO}_{3-d}$ which, because of oxygen deficiency, distorts to an orthorhombic unit cell. The $\mathrm{AMO}_{3}$ unit cell, depicted in Figure 1 ( $n=$ infinity), contains strontium (green spheres) coordinated by twelve oxygen atoms whilst iron is located in an octahedral array of oxygen (red spheres).

Fluorination of $\mathrm{SrFeO}_{3-d}$ was achieved by mixing with poly(vinylidene fluoride) and heating the mixture at $400{ }^{\circ} \mathrm{C}$ for 24 hours in flowing nitrogen. The initial characterisation $^{7}$ by $\mathrm{X}$-ray powder diffraction showed that fluorination resulted in a material with larger cell parameters consistent with the partial replacement of oxygen by fluorine (while X-ray diffraction suggested cubic symmetry, subsequent neutron diffraction studies showed that the cell symmetry was actually orthorhombic). ${ }^{57} \mathrm{Fe}$ Mössbauer spectroscopy demonstrated $^{[7]}$ that fluorination induced a reduction of the oxidation state of iron from $\mathrm{Fe}^{4+} / \mathrm{Fe}^{3+}$ in $\mathrm{SrFeO}_{3-d}$ to $\mathrm{Fe}^{3+}$ in the compound $\mathrm{SrFeO}_{2} \mathrm{~F}$.

Subsequent investigations ${ }^{[8]}$ of $\mathrm{SrFeO}_{2} \mathrm{~F}$ by magnetometry in the temperature range $10-400 \mathrm{~K}$ showed small aligned moments indicating the absence of ferro- or ferrimagnetism and the separation of field cooled and zero field cooled magnetisations at temperatures around $300 \mathrm{~K}$. The ${ }^{57} \mathrm{Fe}$ Mössbauer spectra recorded between 80 and $700 \mathrm{~K}$ are shown in Figure 2. The spectra recorded between 285 and $650 \mathrm{~K}$ showed clear splitting of all the lines contributing to the sextet pattern and showed increasing line-widths and decreasing magnitudes of magnetic hyperfine field until, at $700 \mathrm{~K}$, the magnetic field collapsed to a quadrupole split absorption indicative of the paramagnetic state. The variation of the average magnetic hyperfine field with increasing temperature enabled a magnetic ordering temperature of ca. $685 \mathrm{~K}$ to be deduced for $\mathrm{SrFeO}_{2} \mathrm{~F}$. The spectra recorded

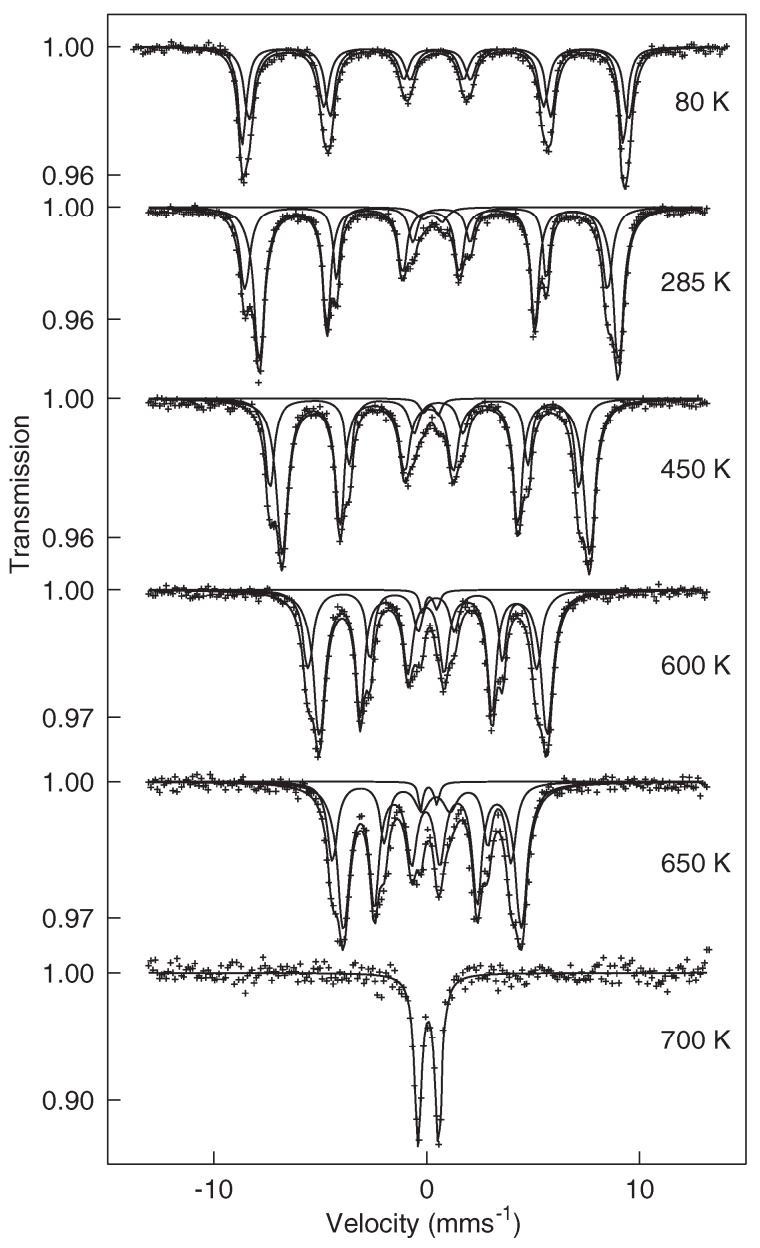

Figure 2. Mössbauer spectra recorded from $\mathrm{SrFeO}_{2} \mathrm{~F}$ between 80 and $700 \mathrm{~K}$. Reproduced with permission from Ref. [8].

in the temperature range $285-700 \mathrm{~K}$ were interpreted in terms of a model in which each $\mathrm{Fe}^{3+}$ ion has four $\mathrm{O}^{2-}$ and two $\mathrm{F}^{-}$ions in the nearest neighbour anion shell corresponding to charge neutrality within the perovskite-related cell. In this case there are two types of arrangements for the fluoride ions, that with the two $\mathrm{F}^{-}$ions at opposite corners of the octahedron (trans arrangement) and that where $\mathrm{F}^{-}$is located at adjacent corners (cis arrangement). The spectral areas of the two components in the spectra recorded between 285 and $650 \mathrm{~K}$ were interpreted in terms of a model involving cis and trans arrangements of two $\mathrm{F}^{-}$ions per perovskite-related unit cell and a single antiferromagnetic axis.

The ${ }^{57} \mathrm{Fe}$ Mössbauer spectra recorded from $\mathrm{SrFeO}_{2} \mathrm{~F}$ between 10 and $317 \mathrm{~K}$ are collected in Figure 3 and are different in that they show no splitting of the spectral lines but significant broadening of each line contributing to the sextet pattern. The difference between these spectra recorded below $c a .300 \mathrm{~K}$ and those above $c a .300 \mathrm{~K}$ is significant. 


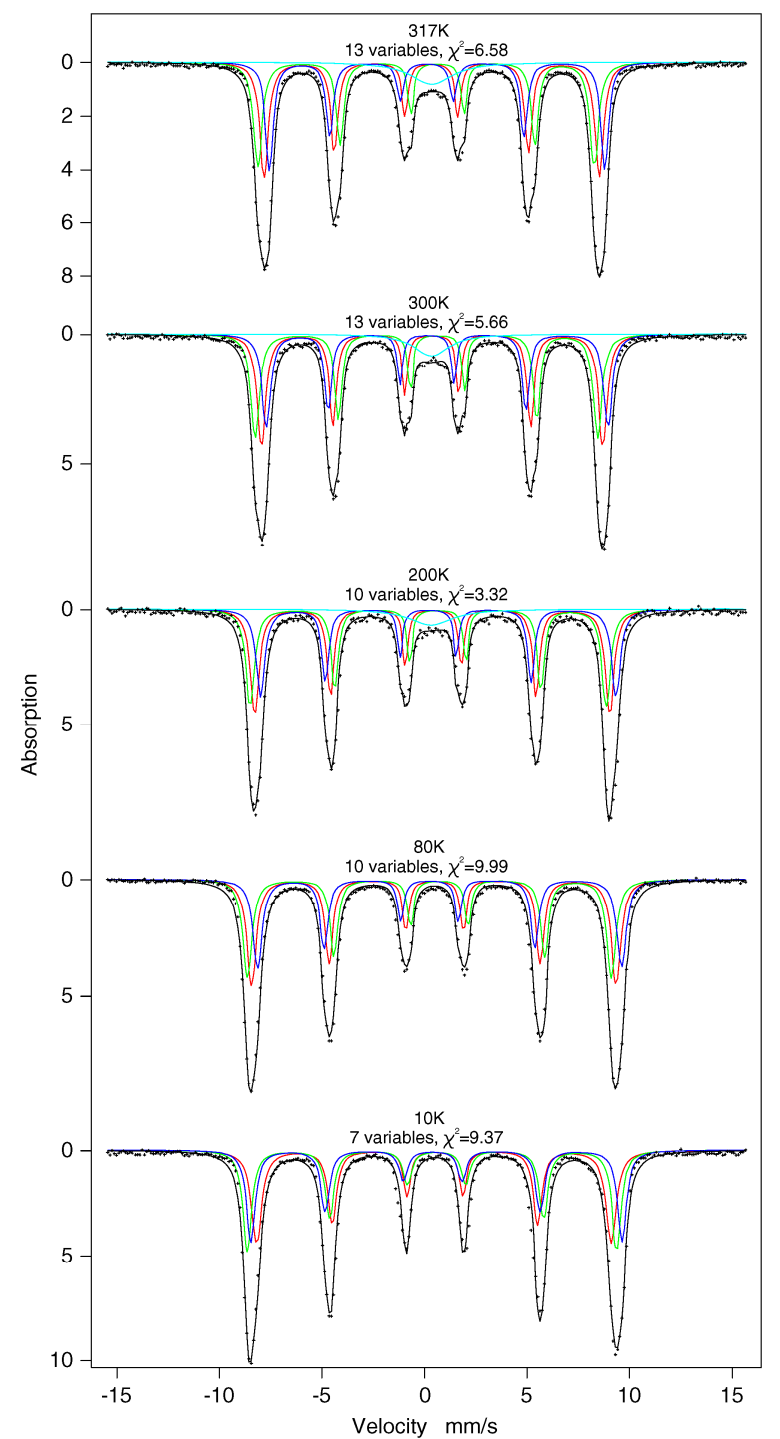

Figure 3. Mössbauer spectra recorded from $\mathrm{SrFeO}_{2} \mathrm{~F}$ between 10 and $317 \mathrm{~K}$. Reproduced with permission from Ref. [8].

Several different models were initially used to fit the spectra recorded between 10 and $310 \mathrm{~K}$ and at least three sextet components found to be required to achieve a reasonable fit and were interpreted in terms of a model in which the $\mathrm{Fe}^{3+}$ moments were randomly orientated with respect to any axis of maximum electric field gradient (EFG). For spectra between 200 and $317 \mathrm{~K}$ an additional non-magnetic doublet component arising from an impurity phase was also required.

The Mössbauer results, taken together with the magnetisation data, were interpreted in terms of $\mathrm{SrFeO}_{2} \mathrm{~F}$ ordering into an antiferromagnetic state at $T_{\mathrm{N}}=c a .685 \mathrm{~K}$ which persists as the temperature is decreased to $c a .300 \mathrm{~K}$. Below this temperature a state characterised by random spin orientation occurs, which shows different ground states in field cooled and zero field cooled conditions. The randomness was associated with the substitution by fluorine on the oxygen anion site causing different superexchange $\mathrm{Fe}^{3+}-\mathrm{O}^{2-}-\mathrm{Fe}^{3+}$ and $\mathrm{Fe}^{3+}-\mathrm{F}^{-}-\mathrm{Fe}^{3+}$ pathways. The significance of the work 7,8 is vested in it showing that the magnetic structure of $\mathrm{SrFeO}_{2} \mathrm{~F}$ is significantly more complex than that of the antiferromagnetic structurally related $\mathrm{PbFeO}_{2} \mathrm{~F}^{[9]}$ in which the trans configuration of fluorine in the distribution of anions around $\mathrm{Fe}^{3+}$ is favoured over the cis arrangement. The differences may be related to the lower temperature synthesis route to produce $\mathrm{SrFeO}_{2} \mathrm{~F}$ in contrast to the high pressure, high temperature synthesis route needed to produce $\mathrm{PbFeO}_{2} \mathrm{~F}$.

\section{$\mathrm{SrFe}_{1-x} \mathrm{Sn}_{\mathrm{x}} \mathrm{O}_{3-y} \mathrm{~F}_{\boldsymbol{y}}$}

The fluorination of orthorhombic $\mathrm{SrFeO}_{3-d}$ was followed by attempts to fluorinate the $\mathrm{SrFeO}_{3-d}$ phase in which iron had been partially replaced by other metals. The first of these studies $^{[10]}$ involved tin-doped materials of composition $\mathrm{SrFe}_{0.69} \mathrm{Sn}_{0.31} \mathrm{O}_{2.94}$ and $\mathrm{SrFe}_{0.46} \mathrm{Sn}_{0.54} \mathrm{O}_{2.88}{ }^{57} \mathrm{Fe}$ Mössbauer spectroscopy indicated that iron in these phases is present as $\mathrm{Fe}^{5+}$ and $\mathrm{Fe}^{3+}$. The disproportionation of $\mathrm{Fe}^{4+}$ in $\mathrm{SrFeO}_{3-d}$ to $\mathrm{Fe}^{5+}$ and $\mathrm{Fe}^{3+}$ upon substitution of $\mathrm{Sn}^{4+}$ (as demonstrated by EXAFS) on the iron site was associated with the reduction of lattice strain.

The two materials were fluorinated by reaction with poly(vinylidene fluoride) at $400{ }^{\circ} \mathrm{C}$ in flowing nitrogen to give products of composition $\mathrm{SrFe}_{0.69} \mathrm{Sn}_{0.31} \mathrm{O}_{2.31} \mathrm{~F}_{0.69}$ and $\mathrm{SrFe}_{0.46} \mathrm{Sn}_{0.54} \mathrm{O}_{2.54} \mathrm{~F}_{0.46}$ with larger unit cells than the parent oxides. The ${ }^{57} \mathrm{Fe}$ Mössbauer spectra recorded between 10 and $300 \mathrm{~K}$ are shown in Figure 4. The results showed that all the $\mathrm{Fe}^{5+}$ in the pure oxide is reduced to $\mathrm{Fe}^{3+}$ in the fluorinated samples (and was consistent with the increased iron to oxygen or fluorine distances as revealed by EXAFS). The results were interpreted in terms of fluorination involving both replacement of some oxide ions by fluoride ions and the filling of vacant anion sites by fluoride ions. Furthermore, all the spectra except that recorded from $\mathrm{SrFe}_{0.46} \mathrm{Sn}_{0.54} \mathrm{O}_{2.54} \mathrm{~F}_{0.46}$ at $300 \mathrm{~K}$ showed the coexistence of magnetic and non-magnetic components and the proportion of the sextet component was found to decrease with increasing tin content and with increasing temperature.

The coexistence of the sextet and doublet components in the ${ }^{57} \mathrm{Fe}$ Mössbauer spectra was interpreted in terms of the presence of clusters or networks of coupled $\mathrm{Fe}^{3+}$ ions with the superexchange coupling being broken by $\mathrm{Sn}^{4+}$ ions which consequently limit the size of the networks. Hence networks larger than a critical size at a given temperature give rise to the magnetic sextet components whilst those less than critical size give rise to the non-magnetic doublet component. The increase in tin content resulted in increased disruption of the magnetically coupled networks 

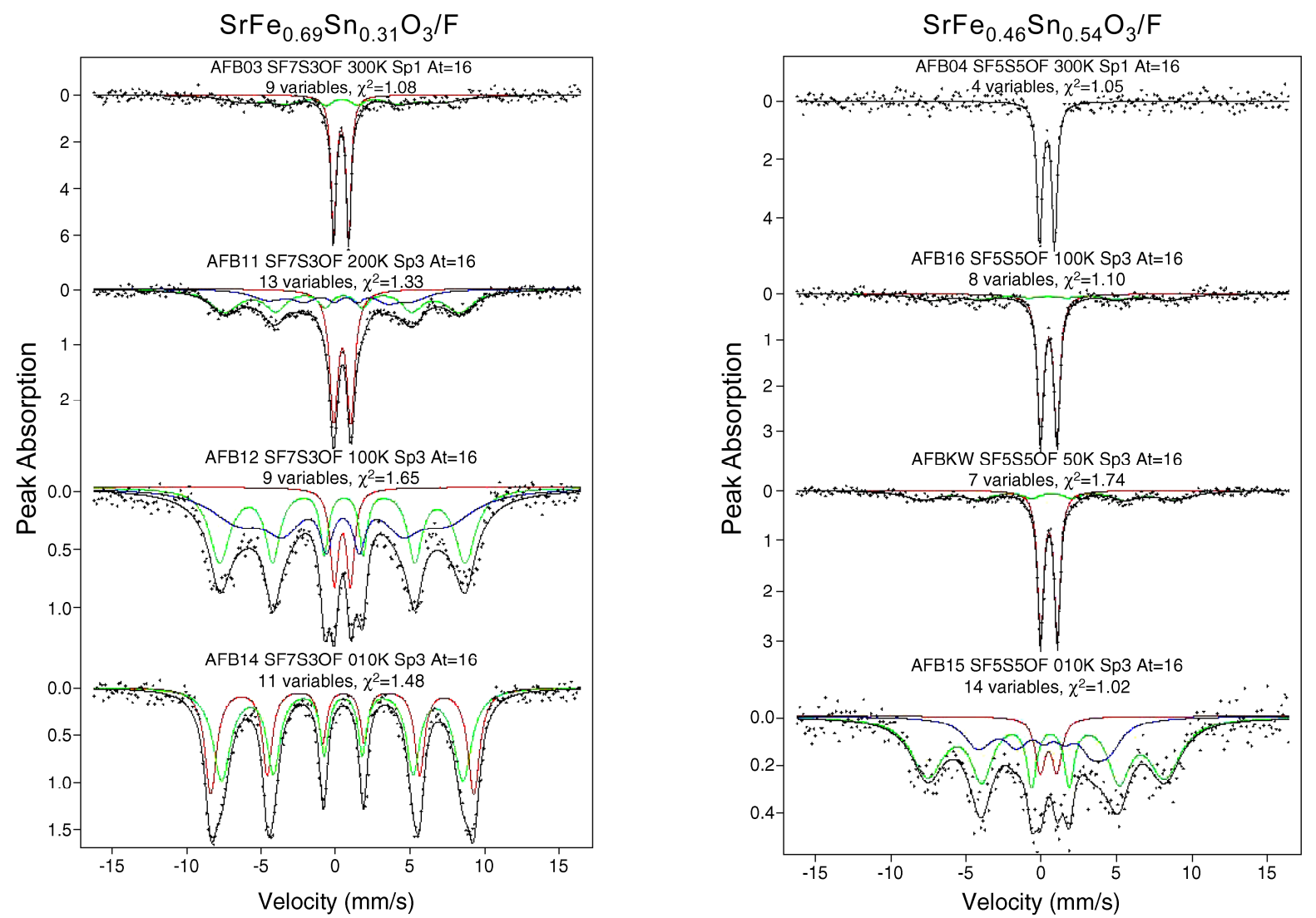

Figure 4. Mössbauer spectra recorded from $\mathrm{SrFe}_{0.69} \mathrm{SnO}_{2.31} \mathrm{~F}_{0.69}$ and $\mathrm{SrFe}_{0.46} \mathrm{Sn}_{0.54} \mathrm{O}_{2.54} \mathrm{~F}_{0.46}$ between 10 and 300 K. Reproduced with permission from Ref. [10].

and an increase in the non-magnetic component in the Mössbauer spectrum. Similarly, for a given tin content, increasing temperature induced more facile disruption of the magnetically ordered networks such that the temperature at which the doublet and sextet components have equal aeas the blocking temperature in superparamagnetism terminology - was evaluated as $T_{B}=c a .275 \mathrm{~K}$ for $\mathrm{SrFe}_{0.69} \mathrm{Sn}_{0.31} \mathrm{O}_{2.31} \mathrm{~F}_{0.69}$ and $T_{\mathrm{B}}=c a .40 \mathrm{~K}$ for $\mathrm{SrFe}_{0.46} \mathrm{Sn}_{0.54} \mathrm{O}_{2.54} \mathrm{~F}_{0.46}$.

\section{$\mathrm{La}_{1-x} \mathrm{Sr}_{x} \mathrm{Fe}_{1-y} \mathrm{Co}_{y} \mathrm{O}_{3-d} / \mathrm{F}$}

Fluorinated derivatives of phases in which cation substitution had been performed on both the $A$ and $M$ sites of the perovskite-related $\mathrm{AMO}_{3}$ structure have also been examined by Mössbauer spectroscopy. ${ }^{[11]}$ Fluorination was achieved by reaction of the pure oxides with poly(vinylidene fluoride) at $400^{\circ} \mathrm{C}$ in flowing nitrogen. X-ray absorption and Mössbauer spectroscopy showed a reduction in the oxidation state of iron and/or cobalt upon fluorination. The fluorinated materials gave complex magnetically split Mössbauer spectra reflecting the interactions between $\mathrm{Fe}^{3+}$ ions which are not possible in the pure oxides which contain $\mathrm{Fe}^{4+}$ and $\mathrm{Fe}^{3+}$.

\section{$\mathrm{BaFeO}_{2} \mathrm{~F}$}

A cubic phase of composition $\mathrm{BaFeO}_{2} \mathrm{~F}$ was made by low temperature fluorination of $\mathrm{BaFeO}_{3-x}$ at $400{ }^{\circ} \mathrm{C}$ in flowing nitrogen using poly(vinylidene) fluoride. ${ }^{[12,13]}$ The magnetic properties were found to be substantially different from the related compound $\mathrm{SrFeO}_{2} \mathrm{~F}$ (see above). Mössbauer spectra collected between 400 and $650 \mathrm{~K}$ showed decreasing magnitudes of magnetic hyperfine field with increasing temperature and from the variation of the average magnetic hyperfine field with increasing temperature (Figure 5) a magnetic ordering temperature of $c a .645 \mathrm{~K}$ was deduced, some $40 \mathrm{~K}$ lower than the ordering temperature for $\mathrm{SrFeO}_{2} \mathrm{~F}$. The Mössbauer spectra recorded between 10 and $300 \mathrm{~K}$ were analysed in terms of the random occupation by fluorine of the anion sites assuming a charge neutral perovskite-related unit cell. In this material neutron diffraction indicated a large displacement of the iron off-site and established the $\mathrm{Fe}^{3+}$ moments to be ordered in a G-type antiferromagnetic structure. Magnetisation measurements indicated the presence of a weak ferromagnetic moment that was assigned to the canting of the antiferromagnetic structure. 


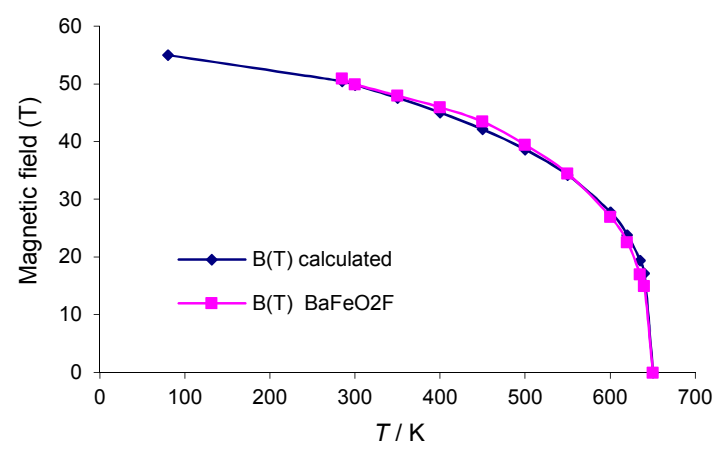

Figure 5. Variation of the magnetic hyperfine field in $\mathrm{BaFeO}_{2} \mathrm{~F}$ with temperature. Reproduced with permission Ref. [13].

\section{$\mathrm{Ba}_{2} \mathrm{SnO}_{2.5} \mathrm{~F}_{3} \cdot x \mathrm{H}_{2} \mathrm{O}$}

Ruddlesden-Popper phases of general formula $A_{n+1} \mathrm{M}_{n} \mathrm{O}_{3 n+1}$ may be viewed as intergrowths between perovskite and rock salt units. The situation where $n=1$ is also known as the $\mathrm{K}_{2} \mathrm{NiF}_{4}$-type structure and is depicted in Figure 1. These $n=1$ phases have also attracted attention for fluorination and an example, involving ${ }^{119} \mathrm{Sn}$ Mössbauer spectroscopy, reported ${ }^{[14]}$ on the fluorination of $\mathrm{Ba}_{2} \mathrm{SnO}_{4}$ through a low temperature reaction at $240{ }^{\circ} \mathrm{C}$ with $\mathrm{ZnF}_{2}$ in flowing nitrogen. $\mathrm{X}$-ray and neutron powder diffraction showed fluorination to result in a significant enlargement by $c a$. $3 \AA$ along the $c$-axis of the unit cell precursor oxide. A structural model based on the perovskite-related $\mathrm{K}_{2} \mathrm{NiF}_{4}$-type structure of the oxide was proposed in which there was direct replacement of oxygen in octahedral $\mathrm{SnO}_{6}$ units by fluorine as well as the presence of $\mathrm{F}^{-}$at interstitial sites between $\mathrm{BaO}$ rock salt layers. Atomistic computer modelling indicated that apical fluorine substitution is favoured. The structural model was supported by the results of ${ }^{19} \mathrm{~F}$ and

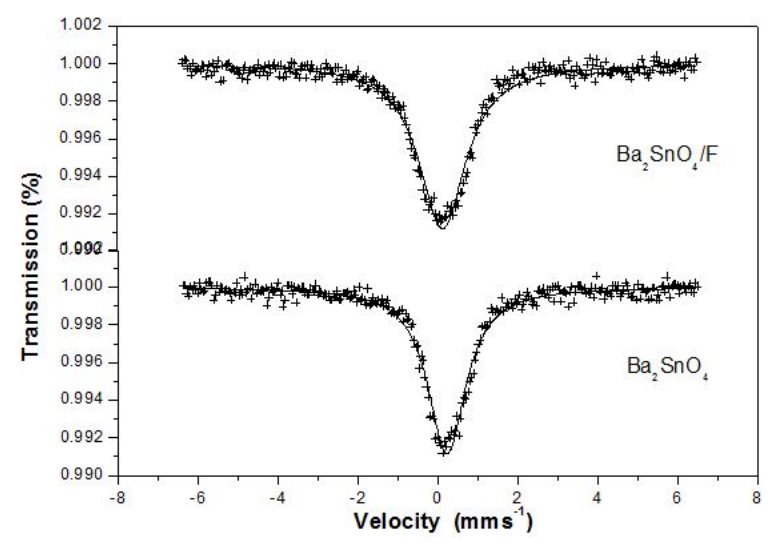

Figure 6. ${ }^{119} \mathrm{Sn}$ Mössbauer spectra recorded from $\mathrm{Ba}_{2} \mathrm{SnO}_{4}$ and its fluorinated derivative at $77 \mathrm{~K}$. Reproduced with permission from Ref. [14].
${ }^{119}$ Sn MAS NMR spectroscopy as well as tin K- and barium $\mathrm{K}$-edge EXAFS. Thermal analysis revealed the presence of water in the synthesised material and this was assigned to interstitial sites.

The ${ }^{119} \mathrm{Sn}$ Mössbauer spectrum recorded from $\mathrm{Ba}_{2} \mathrm{SnO}_{4}$ at $77 \mathrm{~K}$ (Figure 6) was composed of a single absorption with chemical isomer shift of $0.22(1) \mathrm{mms}^{-1}$ and the spectrum recorded from the fluorinated derivative was similar (Figure 6) but with a smaller chemical isomer shift of $0.12(1) \mathrm{mms}^{-1}$ indicative of the electron withdrawing effect of electronegative fluorine on the electron density around $\mathrm{Sn}^{4+}$. The result was endorsed by tin K-edge XANES.

\section{$\mathrm{Sr}_{3} \mathrm{Fe}_{2} \mathrm{O}_{5+x} \mathrm{~F}_{2-x}$}

$\mathrm{Sr}_{3} \mathrm{Fe}_{2} \mathrm{O}_{7-x}$ is a $n=2$ Ruddlesden-Popper phase (see Figure 1) in which complete filling of the ideal oxygen anion sites within the perovskite and rock salt layers would lead to a total oxygen content of 7.0. An interesting additional aspect of these phases is that they also have the possibility of incorporating anions into interstitial fluorite-type positions within the rock salt layers. $\mathrm{Sr}_{3} \mathrm{Fe}_{2} \mathrm{O}_{7-x}$ might nominally be expected to contain mixed $\mathrm{Fe}^{3+} / \mathrm{Fe}^{4+}$ species. However, ${ }^{57} \mathrm{Fe}$ Mössbauer spectroscopy has suggested ${ }^{[15-20]}$ the disproportionation of $\mathrm{Fe}^{4+}$ into $\mathrm{Fe}^{3+}$ and $\mathrm{Fe}^{5+}$. Fluorination of this system has also been examined ${ }^{[21]}$ by reducing $\mathrm{Sr}_{3} \mathrm{Fe}_{2} \mathrm{O}_{7-x}$ to $\mathrm{Sr}_{3} \mathrm{Fe}_{2} \mathrm{O}_{6}$ and treating with gaseous fluorine to give $\mathrm{Sr}_{3} \mathrm{Fe}_{2} \mathrm{O}_{6} \mathrm{~F}_{0.87}$ which also contained $\mathrm{Fe}^{3+}$ and $\mathrm{Fe}^{5+}$. Subsequently ${ }^{[22]}$ a higher degree of fluorine content was achieved in a material of composition $\mathrm{Sr}_{3} \mathrm{Fe}_{2} \mathrm{O}_{5.44} \mathrm{~F}_{1.56}$ in which all the normal anion sites were filled by using polytetrafluoroethylene (PTFE) as the fluorination agent.

We have recentlyy ${ }^{[23]}$ fluorinated $\mathrm{Sr}_{3} \mathrm{Fe}_{2} \mathrm{O}_{7-x}$ by mixing with poly(vinylidene fluoride) (PVDF) in 1:1, 1:2 and 1:2.8 molar ratios and heating at $375^{\circ} \mathrm{C}$. X-ray powder diffraction showed successful fluorination with the unit cell volumes increasing with increasing levels of PVDF. Rietveld refinement of the powder X-ray diffraction data from the 1:1 sample indicated complete filling of the normal anion sites and a composition $\mathrm{Sr}_{3} \mathrm{Fe}_{2} \mathrm{O}_{5+x} \mathrm{~F}_{2-x} .{ }^{57} \mathrm{Fe}$ Mössbauer spectroscopy (Figure 7) showed this phase to contain both $\mathrm{Fe}^{3+}$ and $\mathrm{Fe}^{4+}$ and a composition $\mathrm{Sr}_{3} \mathrm{Fe}_{2} \mathrm{O}_{5.28} \mathrm{~F}_{1.72}$ was deduced. The phase was considered to be similar to that reported previously[22] by fluorination using PTFE. Our work ${ }^{[23]}$ showed that by using PVDF as the fluorinating agent higher fluorine contents could be achieved. For the 1:2 composition Rietveld refinement of the X-ray powder diffraction data showed complete filling of the normal anion sites and partial filling of the interstitial sites. ${ }^{57} \mathrm{Fe}$ Mössbauer spectroscopy (Figure 8) indicated that all the iron was present as $\mathrm{Fe}^{3+}$ and a composition $\mathrm{Sr}_{3} \mathrm{Fe}_{2} \mathrm{O}_{4} \mathrm{~F}_{4}$ with half the interstitial sites filled was determined. For the sample made with the highest amount of PVDF ${ }^{57} \mathrm{Fe}$ Mössbauer spectroscopy (Figure 9) showed only the presence of $\mathrm{Fe}^{3+}$ and an approximate composition 


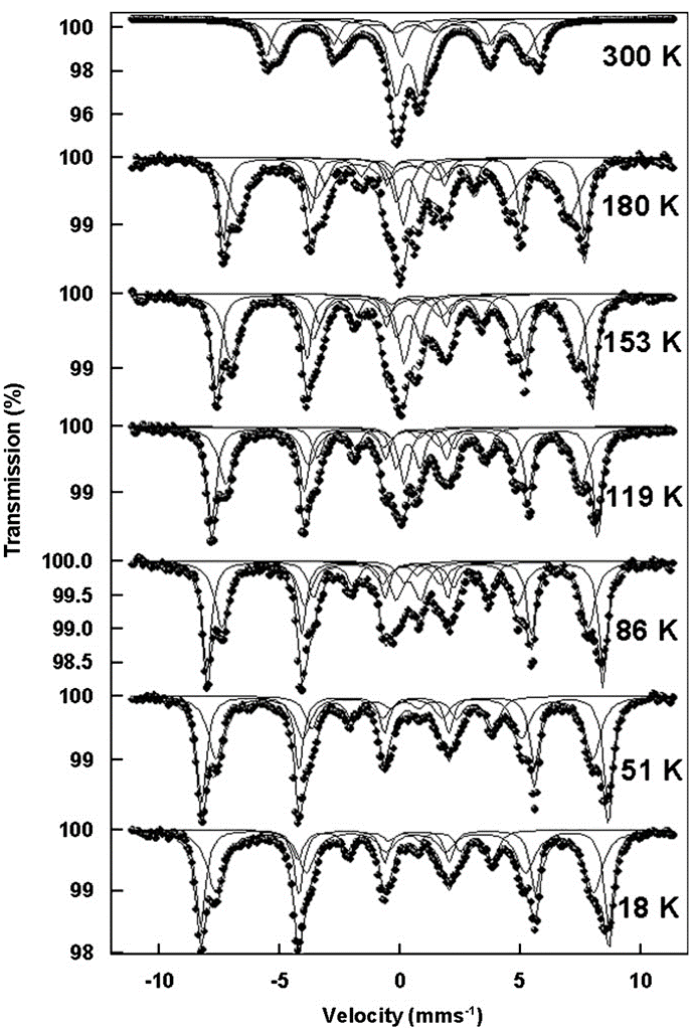

Figure 7. Mössbauer spectra recorded from $\mathrm{Sr}_{3} \mathrm{Fe}_{2} \mathrm{O}_{5.28} \mathrm{~F}_{1.72}$. Reproduced with permission from Ref. [23].

of $\mathrm{Sr}_{3} \mathrm{Fe}_{2} \mathrm{O}_{3} \mathrm{~F}_{6}$ corresponding to complete filling of both the normal anion sites and interstitial sites was proposed.

The Mössbauer data in the temperature ranges 10-300 K (Figures 7, 8 and 9) showed complex magnetic interactions in each of the three phases. For $\mathrm{Sr}_{3} \mathrm{Fe}_{2} \mathrm{O}_{5.28} \mathrm{~F}_{1.72}$ (Figure 7) the paramagnetic component accounting for $\mathrm{ca}$. $30 \%$ of the spectral area at $300 \mathrm{~K}$ decreased in intensity with decreasing temperature until $56 \mathrm{~K}$ when all the $\mathrm{Fe}^{3+}$ ions were magnetically ordered. The quadrupole interactions of the two $\mathrm{Fe}^{3+}$ sextets were quite large and indicative of a distortion of the anion or electronic array around $\mathrm{Fe}^{3+}$ ions and reflective of the presence of both oxygen and more electronegative fluorine. Assuming that fluorine is located on the apical sites (as indicated by refinement of the X-ray diffraction data and bond valence calculations) the magnetic $\mathrm{Fe}^{3+}-\mathrm{O}^{2-}-\mathrm{Fe}^{3+}$ superexchange interactions within planes were associated with the sextet components in the Mössbauer spectra. For $\mathrm{Sr}_{3} \mathrm{Fe}_{2} \mathrm{O}_{4} \mathrm{~F}_{4}$ (Figure 8) the main magnetic component was characterised by relatively large quadrupole interactions indicative of a distorted electronic or anionic environment around $\mathrm{Fe}^{3+}$ and reflective of the presence of more electronegative fluorine in some of the anion sites and local distortions around the $\mathrm{Fe}^{3+}$ ions. For $\mathrm{Sr}_{3} \mathrm{Fe}_{2} \mathrm{O}_{3} \mathrm{~F}_{6}$ (Figure 9) the Mössbauer spectra showed most of the $\mathrm{Fe}^{3+}$ to be paramagnetic at $300 \mathrm{~K}$. Some of the

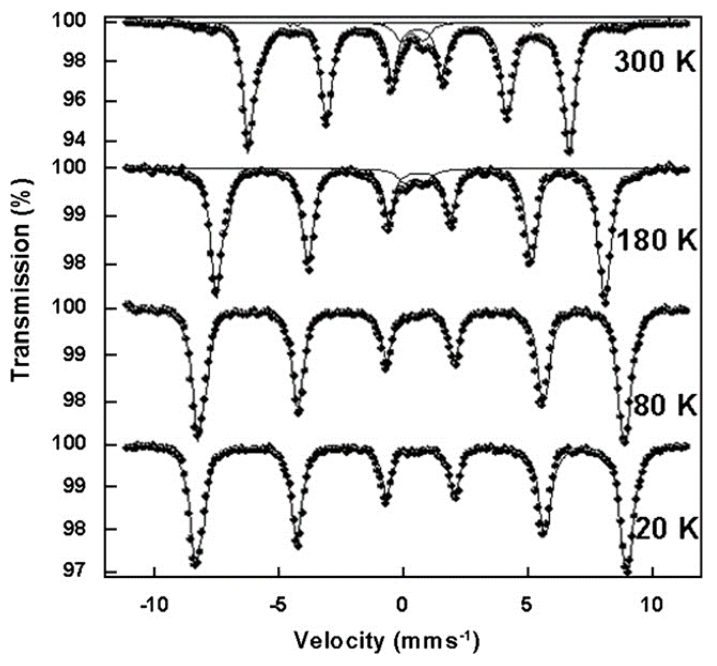

Figure 8. Mössbauer spectra recorded from $\mathrm{Sr}_{3} \mathrm{Fe}_{2} \mathrm{O}_{4} \mathrm{~F}_{4}$. Reproduced with permission from Ref. [23].

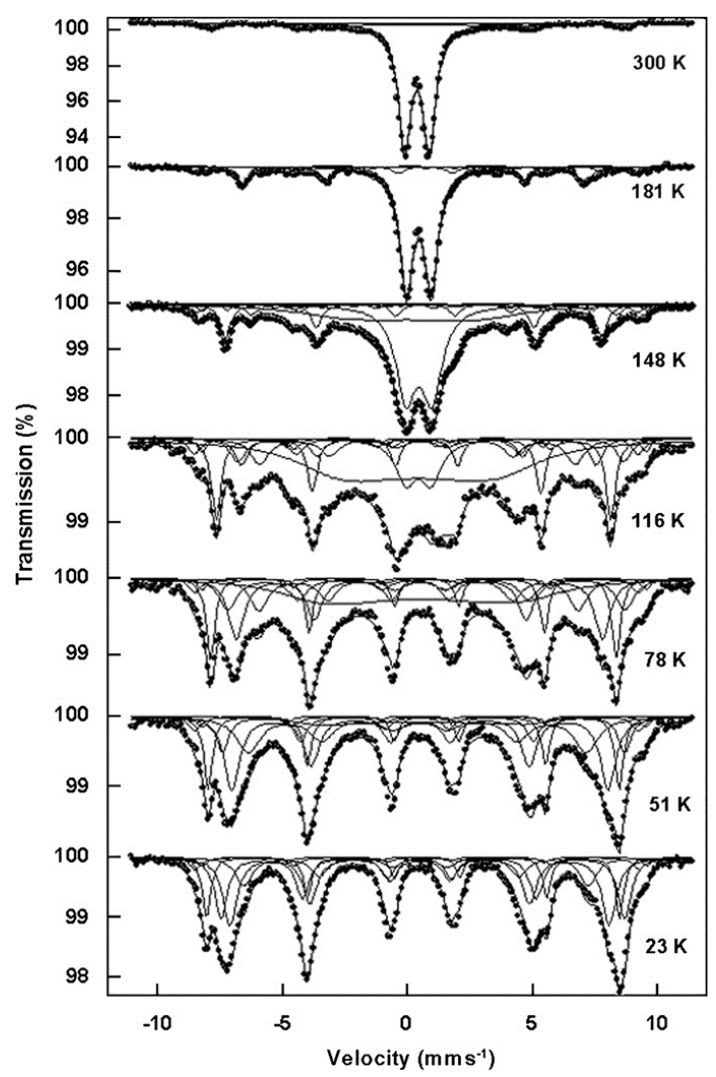

Figure 9. Mössbauer spectra recorded from $\mathrm{Sr}_{3} \mathrm{Fe}_{2} \mathrm{O}_{3} \mathrm{~F}_{6}$. Reproduced with permission from Ref. [23].

sextet components were associated with the presence of impurity phases. The behaviour of the Mössbauer spectra with decreasing temperature was characterised by the coexistence of the paramagnetic doublet and different sextet 


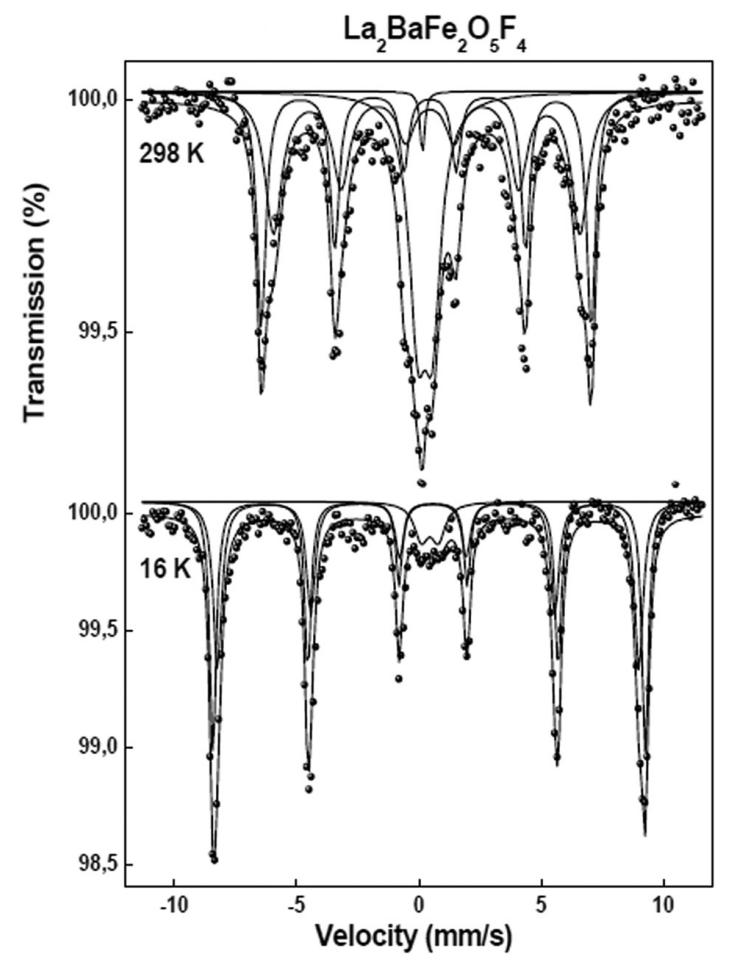

Figure 10. Mössbauer spectra recorded from $\mathrm{La}_{2} \mathrm{BaFe}_{2} \mathrm{O}_{5} \mathrm{~F}_{4}$ at 298 and 16 K. Reproduced with permission from Ref. 24.

components over a large range of temperatures. This was associated with the occurrence of structural disorder reflecting dissimilar configurations around the $\mathrm{Fe}^{3+}$ ions such that they magnetically order at different temperatures. The different configurations were related to the presence of fluorine in equatorial sites such that $\mathrm{Fe}^{3+}-\mathrm{O}^{2-}-\mathrm{Fe}^{3+}$ superexchange pathways are inhibited by $\mathrm{Fe}^{3+}-\mathrm{F}^{-}-\mathrm{Fe}^{3+}$ interactions. The work, overall, showed the versatility of low temperature fluorination of perovskite-related oxides with PVDF for the production of new oxide fluorides with high fluorine contents, and the Mössbauer spectra showed the complexity of magnetic interactions in these phases resulting from the heterogeneity of local oxygen and fluorine compositions around iron ions and their influence on superexchange interactions.

\section{$\mathrm{La}_{2} \mathrm{BaFe}_{2} \mathrm{O}_{5} \mathrm{~F}_{4}$}

We have also recently reported ${ }^{[24]}$ the fluorination of the $n=2$ Ruddlesden-Popper phase (see Figure 1) $\mathrm{La}_{2} \mathrm{BaFe}_{2} \mathrm{O}_{7}$ in a flowing mixture of gaseous $10 \%$ fluorine/90 \% nitrogen at ca. $300{ }^{\circ} \mathrm{C}$ to form $\mathrm{La}_{2} \mathrm{BaFe}_{2} \mathrm{O}_{5} \mathrm{~F}_{4}$. Structural characterisation from neutron powder diffraction data showed the oxide fluoride to contain two fluoride ions in interstitial sites within the rock salt regions and two fluoride ions that had substituted for oxide ions in apical sites within the rock salt layers. The material antiferromagnetically ordered at temperatures below ca. $500 \mathrm{~K}$.
The ${ }^{57} \mathrm{Fe}$ Mössbauer spectra recorded from $\mathrm{La}_{2} \mathrm{BaFe}_{2} \mathrm{O}_{5} \mathrm{~F}_{4}$ are shown in Figure 10. The major part (ca. $97 \%)$ of the spectrum recorded at $298 \mathrm{~K}$ differed from that recorded ${ }^{[25]}$ from $\mathrm{La}_{2} \mathrm{BaFe}_{2} \mathrm{O}_{7}$ at $298 \mathrm{~K}$ in the appearance of a significant (ca. $25 \%$ ) paramagnetic $\mathrm{Fe}^{3+}$ component. The lower intensity of the paramagnetic doublet at $16 \mathrm{~K}$ (ca. $6 \%$ ) suggested that the fluorination process induces a decrease in particle size which is represented by the paramagnetic doublet observed at 298 $\mathrm{K}$. At lower temperatures the small particle $\mathrm{La}_{2} \mathrm{BaFe}_{2} \mathrm{O}_{5} \mathrm{~F}_{4}$ would be expected to magnetically order and give a smaller paramagnetic contribution to the spectrum. This was confirmed in the spectrum recorded at $16 \mathrm{~K}$ where the doublet decreased in magnitude to $c a .6 \%$ of the spectral area. The two $\mathrm{Fe}^{3+}$ sextet patterns observed in the spectrum recorded at $16 \mathrm{~K}$ reflect the distribution of lanthanum and barium around the $\mathrm{FeO}_{6}$ octahedra and these components accounted for $c a .94 \%$ of the spectral area. The minor (ca. $3 \%$ ) singlet component in the spectrum recorded at $298 \mathrm{~K}$ was attributed to a barium-doped $\mathrm{LaFeO}_{3}$ impurity phase present in the $\mathrm{La}_{2} \mathrm{BaFe}_{2} \mathrm{O}_{7}$ starting material which magnetically orders at low temperature and becomes incorporated within the dominant sextet patterns observed at $16 \mathrm{~K}$.

An important contribution of the Mössbauer spectra recorded from $\mathrm{La}_{2} \mathrm{BaFe}_{2} \mathrm{O}_{5} \mathrm{~F}_{4}$ was the demonstration that all the iron in $\mathrm{La}_{2} \mathrm{BaFe}_{2} \mathrm{O}_{5} \mathrm{~F}_{4}$ is present as $\mathrm{Fe}^{3+}$ and shows that fluorination of $\mathrm{La}_{2} \mathrm{BaFe}_{2} \mathrm{O}_{7}$ is achieved without oxidation of iron. This is in contrast with the situation when similar phases containing manganese are fluorinated and manganese is oxidised. This was attributed to the higher reluctance of the $d^{5} \mathrm{Fe}^{3+}$ ion to oxidation as compared to $\mathrm{Mn}^{3+}$.

\section{CONCLUSION}

Our investigations of the fluorination of perovskite-related structures have produced new phases in a range of materials. Of particular importance has been the development of low temperature routes for achieving higher fluorine contents. The structural characterisation of these materials has given new insight as to how fluorine might accommodate itself within these structures. Mössbauer spectroscopy has shown itself to be an important technique for monitoring the changes in oxidation state upon fluorination. It has also revealed the complexity of magnetic interactions within the new oxide fluorides and has sought to relate these to structural properties and the effect of fluorine on superexchange pathways. We are confident that this area of chemistry has many possibilities for the synthesis of new materials in the future and that Mössbauer spectroscopy has a strong place alongside other techniques in the characterisation of these phases. 


\section{REFERENCES}

[1] M. G. Francesconi, C. Greaves, Supercond. Sci. Technol. 1997, 10, A29.

[2] C. Greaves, M. G. Francesconi, Curr. Opin. Solid State Mater. Sci. 1998, 3, 132.

[3] E. E. McCabe, C. Greaves, J. Fluorine Chem. 2007, $128,448$.

[4] D. P. E. Dickson, F. J. Berry, Mössbauer Spectroscopy, 1986, Cambridge University Press, Cambridge.

[5] P. Gutlich, E. Bill, A. X. Trautwein, Mössbauer Spectroscopy and Transition Metal Chemistry, 2011, Springer-Verlag Berlin Heidelburg.

[6] P. R. Slater, J. Fluorine Chem. 2002, 117, 43.

[7] F. J. Berry, X. Ren, R. Heap, P. Slater, M. F. Thomas, Solid State Commun.2005, 134, 621.

[8] F. J. Berry, R. Heap, O. Helgason, E. A. Moore, S. Shim, P. R. Slater, M. F. Thomas, J. Phys.: Condens. Matter 2008, 20, 215207.

[9] Y. Inaguma, J.-M. Greneche, M.-P. Crosnier-Lopez, T. Katsumata, Y. Calago, J.-L. Forguet, Chem. Mater. 2005, 17, 1386.

[10] F. J. Berry, A. F. Bowfield, F. C. Coomer, S. D. Jackson, E. A. Moore, P. R. Slater, M. F. Thomas, A. J. Wright, X. Ren, J. Phys.: Condens. Matter 2009, 21, 256001.

[11] F. J. Berry, X. Ren, R. Heap, P. Slater, M. F. Thomas, J. Phys. Chem. Solids 2008, 69, 2032.

[12] R. Heap, P. R. Slater, F. J. Berry, O. Helgason, A. J. Wright, Solid State Commun. 2007, 141, 467.
[13] F. J. Berry, F. C. Coomer, C. Hancock, O. Helgason, E. A. Moore, P. R. Slater, A. J. Wright, M. F. Thomas, J. Solid State Chem. 2011, 184, 1361.

[14] F. J. Berry, E. Moore, M. Mortimer, X. Ren, R. Heap, P. Slater, M. F. Thomas, J. Solid State Chem. 2008, 181, 2185.

[15] M. Abbate, L. Mogni, F. Prado, A. Caneiro, Phys. Rev. B 2005, 71, 195113.

[16] F. Prado, A. Manthiram, J. Solid State Chem. 2001, $158,307$.

[17] K. Kuzushita, S. Morimoto, S. Nasu, S. Nakamura, J. Phys. Soc. Jpn. 2000, 69, 2767.

[18] P. Adler, J. Solid State Chem. 1997, 130, 129.

[19] S. E. Dann, M. T. Weller, D. B. Currie, M. F. Thomas, A. D. Alrawwas, J. Mater. Chem. 1993, 3, 1231.

[20] S. E. Dann, M. T. Weller, D. B. Currie, J. Solid State Chem. 1992, 97, 179.

[21] G. S. Case, A. L. Hector, W. Levason, R. L. Needs, M. F. Thomas, M. T. Weller, J. Mater. Chem. 1999, 9, 2821.

[22] Y. Tsujimoto, K. Yamaura, N. Hatashi, K. Kodama, N. Igawa, Y. Matsuhita, Y. Katsuya, Y. Shirako, M. Akaogi, E. Takayama-Muromachi, Chem. Mater. 2011, 23, 3652.

[23] C. A. Hancock, T. Herranz, J. F. Marco, F. J. Berry, P. R. Slater, J. Solid State Chem. 2012, 186, 195.

[24] N. N. M. Gurusinghe, J. C. Fones, J. F. Marco, F. J. Berry, C. Greaves, Dalton Trans. 2014, 43, 2038.

[25] N. N. M. Gurusinghe, J. de la Figuera, J. F. Marco, M. F. Thomas, F. J. Berry, C. Greaves, Mater. Res. Bull. 2013, 48, 3537. 